\title{
Retraction Notice: B. Arnold, M. R. Shadnam, Innovation Goals in Software Development for Business Applications, Evolving Trends in Engineering and Technology, Vol. 1, pp. 53-62, 2014 \\ Editorial office of International Journal of Engineering and Technologies \\ Seestrasse 24c, CH-8806 Bach, Switzerland \\ ijet@scipress.com
}

This article has been retracted at the request of the Editor-in-Chief.

The article [1] has appeared to be identical to the paper [2] published by the same authors in the journal Statistics, Optimization and Information Computing (SOI). The paper was submitted to SOI journal six months prior to the Evolving Trends in Engineering and Technology. Our policy is to ensure the publication of high quality scientific manuscripts that were not published before, are not being under review in any other journal or considered for publication anywhere.

In accordance with the Retraction Guidelines of the Committee on Publication Ethics, the Editors have decided to retract the article [1] on the ground of the duplicate publication. The authors of [1] have been informed about this decision and agreed to the retraction. Thus, the paper has been declared retracted and marked properly.

\section{References}

[1] B. Arnold, M. R. Shadnam, Innovation Goals in Software Development for Business Applications, Evolving Trends in Engineering and Technology. 1 (2014) 53-62. DOI: 10.18052/www.scipress.com/ETET.1.53.

[2] R. Arnold, M.R. Shadnam, Innovation Goals in Software Development for Business Applications, Statistics, Optimization and Information Computing. 2(4) (2014) 368-383. DOI: $10.19139 /$ soic.v2i4.53. 